\title{
Clinical characteristics of 78 cases of patients infected with coronavirus disease 2019 in Wuhan, China
}

\author{
LIYING LIN $^{1 *}$, CANMEI ZHONG $^{1 *}$, SHANSHAN RAO ${ }^{2}$, HONGGUANG LIN $^{3}$, \\ RONGFENG HUANG ${ }^{1}$ and FENGLIN CHEN ${ }^{1}$
}

Departments of ${ }^{1}$ Gastroenterology, ${ }^{2}$ Critical Care Medicine and ${ }^{3}$ Respiratory Medicine, Fujian Medical University Union Hospital, Fuzhou, Fujian 350000, P.R. China

Received June 13, 2020; Accepted September 22, 2020

DOI: $10.3892 / \mathrm{etm} .2020 .9439$

\begin{abstract}
Coronavirus disease 2019 (COVID-19) emerged in Wuhan and rapidly spread throughout the world in December 2019. The present study aimed to describe the clinical characteristics and laboratory findings of 78 patients with COVID-19 in order to enhance the understanding of the disease. Medical records and data of 78 patients with COVID-19, including demographics, clinical features, laboratory findings and radiological characteristics, were collected and analyzed. Of the 78 hospitalized patients with COVID-19, the median age was 66.5 years and $48.7 \%$ of patients were male. Hypertension and diabetes were the most common chronic underlying diseases, and the most common symptoms were a cough and a fever. Furthermore, the most common findings on the chest $\mathrm{CT}$ were extensive ground-glass opacity and bilateral shadowing. Anemia and lymphocytopenia were the most common abnormalities identified during routine blood tests. COVID-19 caused early liver renal damage, with $52.9 \%$ of patients displaying elevated D-dimer levels, $98.7 \%$ of patients displaying elevated IL-6 levels and $80.8 \%$ of patients displaying a reduced level of low-density lipoprotein cholesterol (LDL-C). In the present single-center case study of 78 patients with COVID-19 in Wuhan, China, the patients displayed abnormal routine blood tests, liver function, renal function and levels of D-dimer, LDL-C and IL-6. Therefore, the development of drugs and vaccines that can be used to prevent and treat infections of COVID-19 is urgently required.
\end{abstract}

Correspondence to: Dr Fenglin Chen or Dr Rongfeng Huang, Department of Gastroenterology, Fujian Medical University Union Hospital, 29 Xinquan Road, Fuzhou, Fujian 350000, P.R. China

E-mail: 29593961@qq.com

E-mail: drchenflxiehe@163.com

${ }^{*}$ Contributed equally

Key words: clinical characteristics, coronavirus disease 2019

\section{Introduction}

In December 2019, in Wuhan, Hubei, China, a number of patients with pneumonia of an unknown cause were confirmed to be infected with a novel coronavirus, which had not been detected in humans or animals previously (1). On January 7 th 2020 , researchers rapidly isolated a novel coronavirus from patients with confirmed infectious pneumonia (2). The pathogen was named SARS-Cov-2 due to its similarity to the coronavirus that causes severe acute respiratory syndrome (SARS-CoV). These infections share $\geq 79 \%$ of the sequence of the subgenus Sarbecovirus ( $\beta-\mathrm{CoV}$ lineage B). SARS-Cov-2 shares only 50\% homology with the coronavirus responsible for Middle East respiratory syndrome (MERS-CoV), which is a member of the Merbecovirus subgenus (3).

The World Health Organization recently assessed that coronavirus disease 2019 (COVID-19) can be classified as a pandemic (4). As of April 25th 2020, a total of 2,719,896 laboratory-confirmed cases had been reported globally (5), but these figures are increasing every day. The spread of COVID-19 among people has been demonstrated to occur via droplets, aerosols, feces and mouth mucus membranes (1). According to recent studies, the most common symptoms were fever, cough, expectoration, myalgia or fatigue, nausea or vomiting and diarrhea. The most common radiologic finding in chest CT was ground-glass opacity $(3,6)$.

The aim of the present study was to describe the clinical characteristics and laboratory findings of patients with COVID-19 admitted to the Z13 Unit of Union Hospital Affiliated to Tongji Medical College of Huazhong University of Science and Technology to improve the understanding of COVID-19 globally.

\section{Materials and methods}

Patients. Patients with confirmed cases of COVID-19 were enrolled from Z13 Unit of Union Hospital Affiliated to Tongji Medical College of Huazhong University of Science and Technology between February 14th 2020 and March 14th 2020. Only laboratory-confirmed cases were enrolled in the present study, which were previously diagnosed by a positive result from a reverse transcription-quantitative PCR (RT-qPCR) of nasal and pharyngeal swab specimens. All patients enrolled in 
the present study were non-severe. COVID-19 and the degree of severity was diagnosed on the basis of the latest version of the guidelines of Diagnosis and Treatment of Pneumonitis Caused by the novel coronavirus, including the fourth, fifth, and sixth versions, which were issued by the National Health Commission of China (7).

Data collection. The medical records and data of patients were extracted on admission from electronic medical records, and included demographics, clinical features, laboratory findings and characteristics of the chest $\mathrm{CT}$. The aforementioned data were collected and reviewed by the doctors who had been treating the patients with COVID-19, and were then entered into a computerized database and crosschecked. As the cohort of patients enrolled in the present study and the laboratory tests conducted were not derived from random selection, the statistics of the present study are descriptive only. The normal ranges of laboratory findings are presented in Table I.

Statistical analysis. For categorical variables, the percentage of patients in each category was calculated. Continuous variables were appropriately represented as the median with interquartile or simple ranges. There are no estimates of the missing data. Medians and interquartile ranges (IQRs) were calculated using SPSS software (version 22.0; IBM Corp.).

\section{Results}

General information of patients with COVID-19. Up to March 14th 2020, a total of 78 patients with COVID-19 had been admitted to the Z13 Unit of Union Hospital Affiliated to Tongji Medical College of Huazhong University of Science and Technology, including 40 female patients and 38 male patients. The median age of the patients was 66.5 years (interquartile range, 53.75-70), with $5(6.4 \%)$ patients aged 15-40 years, 27 $(34.6 \%)$ patients aged $41-65$ years and $46(59 \%)$ patients aged $>65$ years. Coexisting conditions were observed in $50 \%$ of patients, including hypertension, diabetes, cerebral infarction, malignant tumor and chronic renal failure. Hypertension and diabetes were the most common chronic underlying diseases in the cohort (Table II).

Symptoms. On admission, the majority of the patients presented with a fever $(65.4 \%)$ or cough $(75.6 \%)$ and $50 \%$ of patients reported fatigue. Other symptoms included sputum production, shortness of breath, myalgia or arthralgia, diarrhea and nausea. Out of the 78 patients, only $4(5.1 \%)$ patients did not display any symptoms (data not shown).

$C T$ findings. All patients enrolled in the present study displayed CT abnormalities. The most common chest CT findings of patients with COVID-19 on admission were ground-glass opacity $(53.8 \%)$ and consolidation shadowing (28.2\%) (Table II).

Routine blood examination. The hemoglobin levels and blood cell count of 77 patients (one patient did not receive a routine blood examination) on admission, including white cell, neutrophil, lymphocyte, platelet and eosinophil counts, are presented in Table III. Anemia was identified in $47.4 \%$
Table I. The normal reference ranges of laboratory findings.

\begin{tabular}{|c|c|}
\hline Parameters & Reference ranges \\
\hline Hemoglobin (male, g/l) & $130-175$ \\
\hline Hemoglobin (female, g/l) & $115-150$ \\
\hline White-cell count, $\mathrm{x} 10$ per $\mathrm{mm}^{3}$ & $4-10$ \\
\hline Neutrophil count, $x 10$ per $\mathrm{mm}^{3}$ & $1.8-6.3$ \\
\hline Lymphocytes count, $x 10$ per $\mathrm{mm}^{3}$ & $1.1-3.2$ \\
\hline Platelet count, $x 10$ per $\mathrm{mm}^{3}$ & $125-350$ \\
\hline Eosinophilia count, $\mathrm{x} 10$ per $\mathrm{mm}^{3}$ & $0.02-0.52$ \\
\hline Total bilirubin, $\mu \mathrm{mol} / 1$ & $5.1-19.0$ \\
\hline Direct bilirubin, $\mu \mathrm{mol} / 1$ & $1.7-6.8$ \\
\hline Total protein, $\mathrm{g} / \mathrm{l}$ & $64-83$ \\
\hline Albumin, $\mathrm{g} / \mathrm{l}$ & $35-55$ \\
\hline Globulin, $\mathrm{g} / \mathrm{l}$ & $20-30$ \\
\hline Alanine aminotransferase, IU/l & $8-40$ \\
\hline Aspartate aminotransferase, IU/1 & $5-35$ \\
\hline Alkaline phosphatase, IU/l & $40-150$ \\
\hline$\gamma$-Glutamyltranspeptidase, IU/1 & $7-32$ \\
\hline Blood urea nitrogen, $\mathrm{mmol} / \mathrm{l}$ & $2.9-8.2$ \\
\hline Creatinine, $\mu \mathrm{mol} / 1$ & 44-106 \\
\hline Uric acid, $\mu \mathrm{mol} / 1$ & $155-357$ \\
\hline Cystatin C, mg/l & $\leq 1.0$ \\
\hline Total carbon dioxide, $\mathrm{mmol} / \mathrm{l}$ & $21-30$ \\
\hline Prothrombin time, sec & $11-16$ \\
\hline International normalized ratio & $0.8-1.31$ \\
\hline Fibrinogen degradation products, $\mu \mathrm{g} / \mathrm{ml}$ & $\leq 5.0$ \\
\hline D-dimer, $\mu \mathrm{g} / 1$ & $\leq 0.5$ \\
\hline C-reactive Protein, mg/l & $\leq 5.0$ \\
\hline Procalcitonin, mg/l & $\leq 0.5$ \\
\hline Erythrocyte sedimentation rate, $\mathrm{mm} / \mathrm{H}$ & $\leq 15$ \\
\hline Ferritin, $\mu \mathrm{g} / 1$ & $\leq 4.6$ \\
\hline $\mathrm{CD}^{+}{ }^{+}$total T-lymphocytes, $\%$ & $58.17-84.22$ \\
\hline $\mathrm{CD}^{+}$T-lymphocyte, $\%$ & $25.34-51.37$ \\
\hline CD8 ${ }^{+}$T-lymphocyte, $\%$ & $14.23-38.95$ \\
\hline $\mathrm{CD}^{+} / \mathrm{CD}^{+}{ }^{+}$ & $0.41-2.72$ \\
\hline IL-6, pg/ml & $\leq 2.9$ \\
\hline $\mathrm{TNF}-\alpha, \mathrm{pg} / \mathrm{ml}$ & $\leq 23$ \\
\hline $\mathrm{IL}-4, \mathrm{pg} / \mathrm{ml}$ & $\leq 3.2$ \\
\hline $\mathrm{IL}-2, \mathrm{pg} / \mathrm{ml}$ & $\leq 4.1$ \\
\hline $\mathrm{IL}-10, \mathrm{pg} / \mathrm{ml}$ & $\leq 5.0$ \\
\hline $\mathrm{IFN}-\gamma, \mathrm{pg} / \mathrm{ml}$ & $\leq 18$ \\
\hline $\mathrm{LDH}, \mathrm{U} / 1$ & $109-245$ \\
\hline $\mathrm{CK}, \mathrm{U} / 1$ & $26-140$ \\
\hline CK-MB, U/1 & $\leq 6.6$ \\
\hline cTnI, ng/l & $\leq 26.2$ \\
\hline $\mathrm{BNP}, \mu \mathrm{g} / \mathrm{ml}$ & $\leq 100$ \\
\hline $\mathrm{TG}, \mathrm{mmol} / \mathrm{l}$ & $\leq 1.7$ \\
\hline LDL-c, mmol/1 & $2.7-3.1$ \\
\hline
\end{tabular}

LDH, lactic dehydrogenase; CK, creatine kinase; CK-MB, CK isoenzyme-the Muscle Brain isoenzyme; cTnI, hypersensitive troponin I; $\mathrm{BNP}$, brain natriuretic peptide; TG, triglyceride; IQR, interquartile range; LDL-c, low density lipoprotein cholesterol.

of male patients and $41 \%$ of female patients. Moreover, $14(18.2 \%)$ patients displayed leucopenia and $3(3.9 \%)$ 
Table II. General information of patients with COVID-19.

\begin{tabular}{|c|c|}
\hline Characteristics & All patients, $n=78$ \\
\hline Median (interquartile) age (years) & $66.5(53.75-70)$ \\
\hline \multicolumn{2}{|l|}{ Age groups (years) } \\
\hline $15-40$ & $5(6.4)$ \\
\hline $41-65$ & $27(34.6)$ \\
\hline$>65$ & $46(59)$ \\
\hline \multicolumn{2}{|l|}{$\operatorname{Sex}(\%)$} \\
\hline Male & $38(48.7)$ \\
\hline Female & $40(51.3)$ \\
\hline \multicolumn{2}{|l|}{ Coexisting conditions $(\%)$} \\
\hline Any & $39(50)$ \\
\hline Hypertension & $24(30.8)$ \\
\hline Diabetes & $16(20.5)$ \\
\hline Cerebral infarction & $1(1.3)$ \\
\hline Malignant tumor & $3(3.8)$ \\
\hline Chronic renal failure & $3(3.8)$ \\
\hline \multicolumn{2}{|l|}{ Symptoms (\%) } \\
\hline Fever & $51(65.4)$ \\
\hline Cough & $59(75.6)$ \\
\hline Sputum production & $24(30.8)$ \\
\hline Shortness of breath & $12(15.4)$ \\
\hline Fatigue & $39(50)$ \\
\hline Myalgia or arthralgia & $19(24.4)$ \\
\hline Diarrhea & $13(16.7)$ \\
\hline Nausea & $14(17.9)$ \\
\hline Headache & $0(0)$ \\
\hline Nausea or vomiting & $0(0)$ \\
\hline \multicolumn{2}{|l|}{ Abnormalities on chest CT (\%) } \\
\hline Ground-glass opacity & $42(53.8)$ \\
\hline Bilateral patchy shadowing & $20(25.6)$ \\
\hline Thread net shadowing & $14(17.9)$ \\
\hline Linear shadowing & $13(16.7)$ \\
\hline Consolidation shadowing & $22(28.2)$ \\
\hline
\end{tabular}

COVID-19, coronavirus disease 2019.

patients displayed leukocytosis. Lymphocytopenia was present in $28(36.4 \%)$ patients and thrombocytopenia was identified in $8(10.4 \%)$ patients. Twelve patients displayed lower eosinophilia counts than the lower limit of the reference range.

Assessment of liver function. Among the 78 patients, 14 (17.9\%) patients displayed elevated levels of total bilirubin, whereas elevated direct bilirubin was observed in 7 (9\%) patients. The incidence rates of elevated alanine aminotransferase (ALT), aspartate transaminase (AST), alkaline phosphatase (ALP) and $\gamma$-glutamyl transferase $(\gamma$-GGT) were $17.9,37.2,1.3$ and $43.6 \%$, respectively. Moreover, 36 patients displayed lower total protein counts than the lower limit of the reference range. Levels of albumin were decreased in 27 (34.6\%) the patients. In addition, $55(70.5 \%)$ patients displayed normal serum levels of globulin (Table IV).
Table III. Routine blood examination.

\begin{tabular}{|c|c|}
\hline Parameter & Patient no. \\
\hline \multicolumn{2}{|c|}{ Hemoglobin (Male, g/l) } \\
\hline Median (IQR) & $131(122-138.25)$ \\
\hline$<130(\%)$ & $18 / 38(47.4)$ \\
\hline$>175(\%)$ & $0 / 38(0)$ \\
\hline \multicolumn{2}{|c|}{ Hemoglobin (Female, g/l) } \\
\hline Median (IQR) & $118(111-123)$ \\
\hline$<115(\%)$ & $16 / 39(41)$ \\
\hline$>150(\%)$ & $0 / 39(0)$ \\
\hline \multicolumn{2}{|c|}{ White-cell count, $\mathrm{x} 10$ per $\mathrm{mm}^{3}$} \\
\hline Median (IQR) & $5.51(4.40-7.34)$ \\
\hline$<4(\%)$ & $14 / 77(18.2)$ \\
\hline$>10(\%)$ & 3/77 (3.9) \\
\hline \multicolumn{2}{|c|}{ Neutrophil count, $\mathrm{x} 10$ per $\mathrm{mm}^{3}$} \\
\hline Median (IQR) & $3.37(2.56-5.28)$ \\
\hline$<1.8(\%)$ & $3 / 77(3.9)$ \\
\hline$>6.3(\%)$ & 8/77 (10.4) \\
\hline \multicolumn{2}{|c|}{ Lymphocytes count, $\mathrm{x} 10$ per $\mathrm{mm}^{3}$} \\
\hline Median (IQR) & $1.29(0.91-1.68)$ \\
\hline$<1.1(\%)$ & 28/77 (36.4) \\
\hline$>3.2(\%)$ & $2 / 77(2.6)$ \\
\hline \multicolumn{2}{|c|}{ Platelet count, $\mathrm{x} 10$ per $\mathrm{mm}^{3}$} \\
\hline Median (IQR) & $216(159.5-271)$ \\
\hline$<125(\%)$ & 8/77 (10.4) \\
\hline$>350(\%)$ & $5 / 77(6.5)$ \\
\hline \multicolumn{2}{|c|}{ Eosinophilia count, $\mathrm{x} 10$ per $\mathrm{mm}^{3}$} \\
\hline Median (IQR) & $0.07(0.03-0.12)$ \\
\hline$<0.02$ & $12 / 77(15.6)$ \\
\hline$>0.52$ & $0 / 77(0)$ \\
\hline
\end{tabular}

IQR, interquartile range.

Assessment of renal function. The levels of blood urea nitrogen, creatinine, uric acid, cystatin $\mathrm{C}$ and total carbon dioxide are presented in Table V. Among the 77 patients, $64(83.1 \%)$ patients displayed normal blood urea nitrogen levels. Total creatinine levels $<44 \mu \mathrm{mol} / \mathrm{l}$ were observed in $2(2.6 \%)$ patients, whereas $4(5.2 \%)$ patients displayed total creatinine levels $>106 \mu \mathrm{mol} / \mathrm{l}$. Moreover, 5 (6.6\%) patients out of 76 patients displayed a lower uric acid count than the lower limit of the reference range, whereas 11 (14.5\%) patients displayed a higher uric acid count (one patient missed the blood examination of uric acid and cystatin C). Elevated cystatin $\mathrm{C}$ levels were observed in $64.5 \%$ of patients.

Assessment of coagulation function. The results of the assessment of coagulation function are presented in Table VI. Among the $51 \mathrm{D}$-dimer tests performed, 52.9\% identified elevated D-dimer levels (median, $0.6 \mu \mathrm{g} / \mathrm{l}$; interquartile range, $0.2-1.56 \mu \mathrm{g} / \mathrm{l})$.

Level of infection-related biomarkers. C-reactive protein levels were increased in $34(47.2 \%)$ patients. Only one patient displayed a procalcitonin level $>0.5 \mathrm{mg} / \mathrm{l}$. Among 
Table IV. Assessment of liver function.

\begin{tabular}{|c|c|}
\hline Parameter & Patient no. \\
\hline \multicolumn{2}{|c|}{ Total bilirubin, umol/1 } \\
\hline Median (IQR) & $12.95(10.27-16.92)$ \\
\hline$<5.1(\%)$ & $1 / 78(1.3)$ \\
\hline$>19.0(\%)$ & $14 / 78(17.9)$ \\
\hline \multicolumn{2}{|c|}{ Direct bilirubin, $\mu \mathrm{mol} / 1$} \\
\hline Median (IQR) & $4.0(3.3-5.0)$ \\
\hline$<1.7(\%)$ & $0 / 78(0)$ \\
\hline$>6.8(\%)$ & $7 / 78(9.0)$ \\
\hline \multicolumn{2}{|l|}{ Total protein, g/l } \\
\hline Median (IQR) & $64.9(61.82-67.32)$ \\
\hline$<64(\%)$ & $36 / 78(46.2)$ \\
\hline$>83(\%)$ & $0 / 78(0)$ \\
\hline \multicolumn{2}{|l|}{ Albumin, g/l } \\
\hline Median (IQR) & $36.75(33.08-40.25)$ \\
\hline$<35(\%)$ & $27 / 78(34.6)$ \\
\hline$>55(\%)$ & $0 / 78(0)$ \\
\hline \multicolumn{2}{|l|}{ Globulin, g/l } \\
\hline Median (IQR) & $27.3(24.98-30.43)$ \\
\hline$<20(\%)$ & $2 / 78(2.6)$ \\
\hline$>30(\%)$ & 21/78 (26.9) \\
\hline \multicolumn{2}{|c|}{ Alanine aminotransferase, IU/1 } \\
\hline Median (IQR) & $27(20-37.25)$ \\
\hline$<8(\%)$ & $0 / 78(0)$ \\
\hline$>40(\%)$ & $14 / 78(17.9)$ \\
\hline \multicolumn{2}{|c|}{ Aspartate aminotransferase, IU/1 } \\
\hline Median (IQR) & $25.5(17.75-48)$ \\
\hline$<5(\%)$ & $0 / 78(0)$ \\
\hline$>35(\%)$ & 29/78 (37.2) \\
\hline \multicolumn{2}{|c|}{ Alkaline phosphatase, IU/l } \\
\hline Median (IQR) & $78(67-99.25)$ \\
\hline$<40(\%)$ & $0 / 78(0)$ \\
\hline$>150(\%)$ & $1 / 78(1.3)$ \\
\hline \multicolumn{2}{|c|}{$\gamma$-Glutamyltranspeptidase, IU/1 } \\
\hline Median (IQR) & $28.5(19-48.5)$ \\
\hline$<7(\%)$ & $0 / 78(0)$ \\
\hline$>32(\%)$ & $34 / 78(43.6)$ \\
\hline
\end{tabular}

$\mathrm{IQR}$, interquartile range.

the 45 erythrocyte sedimentation rate (ESR) examinations performed, levels of ESR were increased in 36 (80\%) patients. Only 24 patients received ferritin tests, with 16 patients displaying ferritin levels $>204 \mu \mathrm{g} / \mathrm{l}$ (Table VII).

Measurement of T-lymphocyte subsets. The numbers of total T-lymphocytes were lower than the reference range in $13(16.7 \%)$ patients, but higher in 18 patients $(23.1 \%)$. Among the 78 patients, $6(7.7 \%)$ patients displayed declined CD4 ${ }^{+}$T-lymphocyte counts and 25 (32.1\%) patients displayed elevated counts. Moreover, $\mathrm{CD} 8^{+} \mathrm{T}-\mathrm{lymphocyte}$ counts were elevated in $9(11.5 \%)$ patients and decreased in $9(11.5 \%)$ patients. The ratio of $\mathrm{CD}^{+} \mathrm{T}-$ lymphocytes to
Table V. Assessment of renal function.

\begin{tabular}{lc}
\hline Parameter & Patient no. \\
\hline Blood urea nitrogen, mmol/l & \\
Median (IQR) & $4.2(3.22-5.05)$ \\
$<2.9(\%)$ & $10 / 77(13)$ \\
$>8.2(\%)$ & $3 / 77(3.9)$ \\
Creatinine, $\mu \mathrm{mol} / 1$ & \\
Median $(\mathrm{IQR})$ & $75(66.25-87.5)$ \\
$<44(\%)$ & $2 / 77(2.6)$ \\
$>106(\%)$ & $4 / 77(5.2)$ \\
Uric acid, $\mu \mathrm{mol} / \mathrm{l}$ & \\
Median $(\mathrm{IQR})$ & $277(215.25-328.25)$ \\
$<155(\%)$ & $5 / 76(6.6)$ \\
$>357(\%)$ & $11 / 76(14.5)$ \\
Cystatin C, mg/l & \\
Median $(\mathrm{IQR})$ & $1.08(0.94-1.28)$ \\
$>1.0(\%)$ & $49 / 76(64.5)$ \\
Total carbon dioxide, $\mathrm{mmol} / 1$ & \\
Median (IQR) & $23.6(20.45-26.7)$ \\
$<21$ & $20 / 77(26)$ \\
$>30$ & $2 / 77(2.6)$ \\
\hline
\end{tabular}

$\mathrm{IQR}$, interquartile range.

Table VI. Assessment of coagulation function.

\begin{tabular}{lc}
\hline Parameter & Patient no. \\
\hline Prothrombin time, sec & \\
Median (IQR) & $12.95(10.27-16.92)$ \\
$<11(\%)$ & $0 / 70(0)$ \\
$>16(\%)$ & $2 / 7(2.9)$ \\
International normalized ratio & \\
Median (IQR) & $1.04(0.99-1.10)$ \\
$<0.8(\%)$ & $0 / 70(0)$ \\
$>1.31(\%)$ & $2 / 70(2.9)$ \\
Fibrinogen degradation products, $\mu \mathrm{g} / \mathrm{ml}$ & \\
Median $(\mathrm{IQR})$ & $2.2(1.3-4.7)$ \\
$>5(\%)$ & $12 / 51(23.5)$ \\
D-dimer, $\mu \mathrm{g} / \mathrm{l}$ & \\
Median $(\mathrm{IQR})$ & $0.6(0.21-1.56)$ \\
$>0.5(\%)$ & $27 / 51(52.9)$ \\
\hline
\end{tabular}

IQR, interquartile range.

$\mathrm{CD}^{+}$T-lymphocytes was increased in 25 (32.1\%) patients (Table VIII).

Cytokine detection. A total of 77 out of the 78 patients received cytokine detection. The majority of patients displayed elevated levels of IL-6 (98.7\%). The incidence rates of elevated IL-2, IL-4, IL-10 and TNF- $\alpha$ were 32.5, 53.2, 33.8 and 9.1\%, respectively. IFN- $\gamma$ levels were within the normal range (Table IX). 
Table VII. Level of infection-related biomarkers.

\begin{tabular}{lc}
\hline Parameter & Patient no. \\
\hline C-reactive protein, mg/l & \\
$>5(\%)$ & $34 / 72(47.2)$ \\
Procalcitonin, $\mathrm{mg} / \mathrm{l}$ & \\
$>0.5(\%)$ & $1 / 71(1.4)$ \\
Erythrocyte sedimentation rate, $\mathrm{mm} / \mathrm{H}$ & \\
$>15(\%)$ & $36 / 45(80)$ \\
Ferritin, $\mu \mathrm{g} / \mathrm{l}$ & \\
Median(IQR) & $248.8(132.3-492.95)$ \\
$>4.6(\%)$ & $0 / 24(0)$ \\
\hline
\end{tabular}

IQR, interquartile range.

Table VIII. Measurement of T-lymphocyte subsets.

\begin{tabular}{lc}
\hline Parameter & Patient no. \\
\hline CD3 ${ }^{+}$total T-lymphocytes, $\%$ & \\
Median (IQR) & $78.28(67.34-83.98)$ \\
$<58.17(\%)$ & $13 / 78(16.7)$ \\
$>84.22(\%)$ & $18 / 78(23.1)$ \\
CD4 ${ }^{+}$T-lymphocyte, $\%$ & \\
Median (IQR) & $46.74(36.30-54.33)$ \\
$<25.34(\%)$ & $6 / 78(7.7)$ \\
$>51.37(\%)$ & $25 / 78(32.1)$ \\
CD8 ${ }^{+}$T-lymphocyte, $\%$ & \\
Median (IQR) & $23.67(17.95-31.39)$ \\
$<14.23(\%)$ & $9 / 78(11.5)$ \\
$>38.95(\%)$ & $9 / 78(11.5)$ \\
CD4 ${ }^{+}$CD ${ }^{+}$ & \\
Median (IQR) & $1.79(1.41-2.81)$ \\
$<0.41(\%)$ & $2 / 78(2.6)$ \\
$>2.72(\%)$ & $25 / 78(32.1)$ \\
\hline
\end{tabular}

$\mathrm{IQR}$, interquartile range; $\mathrm{CD}$, cluster of differentiation.

Levels of lactate dehydrogenase $(\mathrm{LDH})$, creatine kinase $(C K)$, creatine kinase-MB, hypersensitive troponin I (cTnI) and brain natriuretic peptide $(B N P)$. The levels of $\mathrm{LDH}, \mathrm{CK}$, CK-MB, cTnI and BNP in blood are presented in Table X. The results indicated that $35.9,18.2,1.4,6.7$ and $11.8 \%$ of patients displayed elevated levels of LDH, CK, CK-MB, cTn and BNP peptide, respectively.

Level of triglyceride (TG) and low-density lipoprotein cholesterol $(L D L-C)$. Elevated levels of TG were observed in $31.5 \%$ of patients, whereas $59(80.8 \%)$ of the 73 patients displayed reduced levels of LDL-C (Table XI).

\section{Discussion}

In the present study, a total of 78 patients with COVID-19 were recruited. The majority of patients were elderly individuals
Table IX. Cytokine detection.

\begin{tabular}{lc}
\hline Parameter & Patient no. \\
\hline IL-6, pg/ml & \\
Median (IQR) & $11.23(6.16-22.78)$ \\
$>2.9(\%)$ & $76 / 77(98.7)$ \\
TNF- $\alpha, \mathrm{pg} / \mathrm{ml}$ & \\
Median (IQR) & $5.39(3.53-11.07)$ \\
$>23(\%)$ & $7 / 77(9.1)$ \\
IL-4, pg/ml & \\
Median (IQR) & $3.34(2.52-4.11)$ \\
$>3.2(\%)$ & $41 / 77(53.2)$ \\
IL-2, pg/ml & \\
Median (IQR) & $3.77(3.00-4.19)$ \\
$>4.1(\%)$ & $25 / 77(32.5)$ \\
IL-10, pg/ml & \\
Median (IQR) & $4.6(3.88-5.29)$ \\
$>5$ (\%) & $26 / 77(33.8)$ \\
IFN- $\gamma$, pg/ml & \\
Median (IQR) & \\
$>18(\%)$ & $3.29(2.56-3.69)$ \\
\hline IQR, interquartile range; IL, interleukin; TNF, tumor necrosis factors; & \\
IFN, interferon. & \\
&
\end{tabular}

Table X. Level of LDH, CK, CK-MB, cTnI and BNP.

\begin{tabular}{lc}
\hline Parameter & Patient no. \\
\hline LDH, U/l & \\
Median (IQR) & $210(170.25-272.5)$ \\
$<109(\%)$ & $1 / 78(1.3)$ \\
$>245(\%)$ & $28 / 78(35.9)$ \\
CK, U/l & \\
Median (IQR) & $65(49.5-126)$ \\
$<26(\%)$ & $1 / 77(1.3)$ \\
$>140(\%)$ & $14 / 77(18.2)$ \\
CK-MB, U/l & \\
Median (IQR) & $0.6(0.4-1.0)$ \\
$>6.6(\%)$ & $1 / 73(1.4)$ \\
cTnI, ng/l & \\
Median $(\mathrm{IQR})$ & $2.7(1.5-6.1)$ \\
$>26.2(\%)$ & $5 / 75(6.7)$ \\
BNP, $\mu$ g/ml & \\
$>100(\%)$ & $6 / 51(11.8)$
\end{tabular}

$\mathrm{IQR}$, interquartile range; $\mathrm{LDH}$, lactic dehydrogenase; $\mathrm{CK}$, creatine kinase; CK-MB, CK isoenzyme-the Muscle Brain isoenzyme; cTnI, hypersensitive troponin I; BNP, brain natriuretic peptide.

(median age, 66.5 years), including 40 female patients and 38 male patients. Similarty to MERSCOV (8), hypertension and diabetes were the most common chronic underlying diseases, which was consistent with the results reported by 
Table XI. Level of TG and LDL-C.

\begin{tabular}{lc}
\hline Parameter & Patient no. \\
\hline TG, mmol/l & \\
Median (IQR) & $1.28(0.9-1.86)$ \\
$>1.7(\%)$ & $23 / 73(31.5)$ \\
LDL-c, mmol/l & \\
Median (IQR) & $2.21(1.89-2.61)$ \\
$<2.7(\%)$ & $59 / 73(80.8)$ \\
$>3.1(\%)$ & $7 / 73(9.6)$ \\
\hline
\end{tabular}

TG, triglyceride; IQR, interquartile range; LDL-c, low density lipoprotein cholesterol.

Chen et al (9), and was potentially an outcome of the weaker immune functions of these patients. Common symptoms upon admission were cough, fever, fatigue, expectoration, myalgia, anepithymia and diarrhea, which were absent in four patients. Consistent with recent studies, future studies should examine asymptomatic patients who come into contact with patients with COVID-19. In the present study, the rate of acute respiratory distress syndrome (ARDS), shock and other serious complications was much lower compared with the rates in early reports $(3,6)$. The low incidence may be associated with the fact that the majority of the cohort consisted of non-severe cases. Furthermore, cases in the previous study were from the early epidemic stage $(3,6)$. Pathogens tend to decrease their virulence to maximize their between-host transmission (6), a phenomenon that occurred in the transmission of MERS-CoV. The global case mortality of MERS-CoV was $\sim 40 \%$, but was $\sim 20 \%$ in the second generation (3).

As for the chest CT, the most common findings in the present study were extensive ground-glass opacity and bilateral patchy shadowing. All of the patients enrolled in the present study displayed CT abnormalities. However, Guan et al (6) reported that $17.9 \%$ of patients with non-severe disease and $2.9 \%$ of patients with severe disease displayed normal chest radiographic or CT upon admission. Yang et al (10) reported that $11.4 \%$ cases did not display abnormalities in the chest CT upon admission and 12 remained normal 10 days later. The aforementioned studies and the results of the present study suggested that a normal chest CT scan cannot rule out the diagnosis of COVID-19.

In terms of routine blood tests, anemia and lymphocytopenia were the most common abnormalities in the present study, which was consistent with the results of a descriptive study of 99 cases of 2019 novel coronavirus pneumonia in Wuhan (9). Guan et al (6) reported a median lymphocyte count of 1,000 per $\mathrm{mm}^{3}$ in 926 non-severe patients, but a median lymphocyte count of 800 per $\mathrm{mm}^{3}$ in severe patients. Ding et al (11) reported that lymphocytopenia was present during the admission and progression stages. Lymphocytes increase gradually during the remission stage and this may be associated with cellular immune deficiency, which suggests that the absolute value of lymphocytes correlates with the severity of new coronavirus infection, indicating that lymphocyte count may serve as a reference index in the clinical diagnosis of COVID-19 infection. Anemia in patients with COVID-19 has been rarely reported. Moreover, the underlying mechanism of action behind the development of anemia is not completely understood. As such, it was speculated that it may be associated with disease consumption.

In the present study, patients with COVID-19 displayed elevated markers of liver function injury, such as ALT and AST. Elevated ALT and AST levels have been previously reported, with an incidence of $14-53 \%(6,12,13)$. In the present study, the incidence rates of elevated ALT and AST were 17.9 and $37.2 \%$, respectively. However, the occurrence of increased $\gamma$-GGT was the highest in all patients on admission in the present study, which may be associated with bile duct cells. A previous study reported that bile duct epithelial cells can express novel coronavirus receptor, angiotensin converting enzyme 2 (ACE2). Therefore, it was hypothesized that the compensatory proliferation of hepatic parenchymal cells derived from bile duct cells leads to upregulated overall expression of ACE2 in liver tissue, which may serve as a potential mechanism underlying COVID-19 infection-mediated liver tissue injury (14). More than a quarter of patients displayed decreased albumin and increased globulin in the present study, which were associated with disease progression and the involvement of humoral immunity. Chen et al (9) reported that severe and critically ill patients can experience a decrease in serum albumin levels to $26.3-30.9 \mathrm{~g} / \mathrm{l}$. In the present study, the albumin levels were lower, which might be due to insufficient consumption and nutrition, but could also be associated with alterations in vascular permeability leading to protein leakage into the tissue gap.

In the present study, on admission, elevated levels of cystatin $\mathrm{C}$ were observed in $>50 \%$ of patients. To the best of our knowledge, there have been no similar reports previously. All nucleated cells can produce cystatin $\mathrm{C}$, which is released constitutively to the bloodstream. Serum cystatin $C$ is less influenced by demographic characteristics and health status compared with creatinine as a direct measurement of glomerular filtration rate (GFR) (15). Cystatin C displays stronger association than estimated GFR with cardiovascular disease, heart failure, hypertension, infection risk, frailty and mortality (15-18). The results of the present study suggested that COVID-19 may cause early renal damage, particularly by altering glomerular filtration ability.

Furthermore, $>50 \%$ of patients displayed elevated levels of D-dimer, which was similar to the results reported by Chen et al (9). Dolhnikoff et al (19) observed a variable number of small fibrinous thrombi in small pulmonary arterioles in areas of damaged and more preserved lung parenchyma in 8 out of 10 cases of COVID-19. The results of the present study support the current concept of hypercoagulative status in patients with COVID-19.

In the present study, cytokine levels were measured in 77 patients with COVID-19. IL-6, IL-2, IL-4, IL-10 and TNF- $\alpha$ levels were demonstrated to be increased, among which increased levels of IL-6, IL-4, IL-10 and IL-2 were the most common. Cytokine storms (CSs) are defined as the excessive and uncontrolled release of proinflammatory cytokines, presenting as systemic inflammation, high inflammatory parameters and multiple organ failure. In coronavirus pneumonia, for example in SARS and MERS, massive 
inflammatory cell infiltration and CSs can lead to acute lung injury, and even ARDS and mortality with rapid virus replication (20-22). Huang et al (12) reported that IL-2, IL-7, IL-10, monocyte chemoattractant protein-1, macrophage inflammatory protein 1A, granulocyte colony-stimulating factor, interferon $\gamma$-induced protein 10 and TNF $\alpha$ levels were higher in patients with severe infection, but IL-6 levels were not significantly different in intensive care unit (ICU) and non-ICU patients. A multicentre cohort study reported significantly higher levels of IL-6 in the non-survival group of patients with COVID-19 compared with the survival group (23). A number of other studies have also reported an increase in IL-6 within patients with severe COVID-19 (9,24,25). In the present study, 76 out of the 77 patients with non-severe COVID-19 displayed elevated levels of IL-6. To date, IL-6 has been used in clinical trials as a therapeutic target for critically ill patients (tocilizumab) and has also been used as an indicator of disease severity $(26,27)$.

In a previous study, 78 patients were analyzed for lymphocyte subsets and cytokines (28). The reduction rate of $\mathrm{CD}^{+}$ $\mathrm{T}$ cells was $28.43 \%$ in the mild group and $61.9 \%$ in the severe group (28). The number of $\mathrm{CD}^{+}$and $\mathrm{CD}^{+} \mathrm{T}$ cells of deceased patients was significantly reduced, but in the state of overactivation, the proportion of highly positive $\mathrm{CCR}^{+} \mathrm{Th} 17$ in $\mathrm{CD}^{+} \mathrm{T}$ cells was increased, and the cytotoxic particles, such as perforin and granolysin, were highly expressed in $\mathrm{CD}^{+}$ $\mathrm{T}$ cells (28). In the present study, increased and decreased $\mathrm{CD}^{+} \mathrm{T}$ cell counts were equal, and the elevated level of CD4 ${ }^{+}$ $\mathrm{T}$ cells was more common, which may be associated with the fact that the majority of patients enrolled in the present study displayed a mild infection.

In the present study, patients with COVID-19 displayed decreased serum LDL-C levels upon admission, which was consistent with the results of a study conducted by Wei et al (29). COVID-19-mediated reductions in LDL-C biosynthesis may be associated with its damage to liver function. COVID-19 may also alter lipid metabolism by inducing acute inflammation. It has been previously reported that proinflammatory cytokines can alter liver function, and reduce cholesterol efflux and transport, thus modulating lipid metabolism (30). COVID-19 may elevate the level of free radicals, which can degrade lipids (31). Furthermore, COVID-19 may alter vascular permeability, leading to cholesterol molecules leaking into the tissue (29).

The sample size of the present study was small, which may have influenced the statistical results. Additionally, a number of patients with typical clinical symptoms or positive chest CT findings displayed negative RT-qPCR results; however, only CDC-confirmed cases were included in the present study. COVID-19 has spread rapidly worldwide. Therefore, developing drugs and vaccines against COVID-19 is of vital importance.

\section{Acknowledgements}

Not applicable.

\section{Funding}

Not applicable.

\section{Availability of data and materials}

The datasets used and/or analyzed during the current study are available from the corresponding author on reasonable request.

\section{Authors' contributions}

FC, RH and LL made substantial contributions to the conception and design of the study. FC, RH, LL, CZ, SR and HL performed the data acquisition, data analysis and interpretation. LL and CZ drafted the article or critical revision for important intellectual content. All authors read and approved the final manuscript.

\section{Ethics approval and consent to participate}

The present study was approved by the Ethics Committee of Union Hospital of Fujian Medical University (the reference number: 2020XGFKY006) and approved to exempt patients from written informed consent.

\section{Patient consent for publication}

Not applicable.

\section{Competing interest}

The authors declare that they have no competing interests.

\section{References}

1. Wang C, Horby PW, Hayden FG and Gao GF: A novel coronavirus outbreak of global health concern. Lancet 395: 470-473, 2020.

2. Jiang F, Deng L, Zhang L, Cai Y, Cheung CW and Xia Z: Review of the clinical characteristics of coronavirus disease 2019 (COVID-19). J Gen Intern Med 35: 1545-1549, 2020.

3. Xu XW, Wu XX, Jiang XG, Xu KJ, Ying LJ, Ma CL, Li SB, Wang HY, Zhang S, Gao HN, et al: Clinical findings in a group of patients infected with the 2019 novel coronavirus (SARS-Cov-2) outside of Wuhan, China: Retrospective case series. BMJ 368: m606, 2020.

4. World Health Organization. Coronavirus disease 2019 (COVID-19) Situation Report-51, (https://www.who.int).

5. World Health Organization. Coronavirus disease 2019 (COVID-19) Situation Report-96, (https://www.who.int)

6. Guan WJ, Ni ZY, Hu Y, Liang WH, Ou CQ, He JX, Liu L, Shan H, Lei CL, Hui DSC, et al: Clinical characteristics of coronavirus disease 2019 in China. N Engl J Med 382: 1708-1720, 2020.

7. General Office of National Health Committee. Notice on the issuance of a program for the diagnosis and treatment of novel coronavirus (2019-nCoV) infected pneumonia (fourth trial version to sixth trial version). http://www.nhc.gov.cn/jkj/ new_index.html.

8. Badawi A and Ryoo SG: Prevalence of comorbidities in the Middle East respiratory syndrome coronavirus (MERS-CoV): A systematic review and meta-analysis. Int J Infect Dis 49: 129-133, 2016.

9. Chen N, Zhou M, Dong X, Qu J, Gong F, Han Y, Qiu Y, Wang J, Liu Y, Wei Y, et al: Epidemiological and clinical characteristics of 99 cases of 2019 novel coronavirus pneumonia in Wuhan, China: A descriptive study. Lancet 395: 507-513, 2020.

10. Yang W, Cao Q, Qin L, Wang X, Cheng Z, Pan A, Dai J, Sun Q, Zhao F, Qu J and Yan F: Clinical characteristics and imaging manifestations of the 2019 novel coronavirus disease (COVID-19): A multi-center study in Wenzhou city, Zhejiang, China. J Infect 80: 388-393, 2020.

11. Ding Q, Lu P,Fan Y,Xia Y and Liu M: The clinical characteristics of pneumonia patients coinfected with 2019 novel coronavirus and influenza virus in Wuhan, China. J Med Virol: March 20, 2020. 10.1002/jmv.25781, 2020. 
12. Huang C, Wang Y, Li X, Ren L, Zhao J, Hu Y, Zhang L, Fan G, $\mathrm{Xu}$ J, Gu X, et al: Clinical features of patients infected with 2019 novel coronavirus in Wuhan, China. Lancet 395: 497-506, 2020.

13. Chinese Digestion Association, Chinese Medical Doctor Association; Chinese Society of Hepatology, Chinese Medical Association: The protocol for prevention, diagnosis and treatment of liver injury in coronavirus disease 2019. Zhonghua Gan Zang Bing Za Zhi 28: 217-221, 2020 (In Chinese).

14. Guan GW, Gao L, Wang JW, Wen XJ, Mao TH, Peng SW, Zhang T, Chen XM and Lu FM: Exploring the mechanism of liver enzyme abnormalities in patients with novel coronavirus-infected pneumonia. Zhonghua Gan Zang Bing Za Zhi 28: 100-106, 2020 (In Chinese).

15. Shlipak MG, Mattes MD and Peralta CA: Update on cystatin C: Incorporation into clinical practice. Am J Kidney Dis 62: 595-603, 2013.

16. Menon V, Shlipak MG, Wang X, Coresh J, Greene T, Stevens L, Kusek JW, Beck GJ, Collins AJ, Levey AS and Sarnak MJ: Cystatin $\mathrm{C}$ as a risk factor for outcomes in chronic kidney disease. Ann Intern Med 147: 19-27, 2007.

17. Sarnak MJ, Katz R, Stehman-Breen CO, Fried LF, Jenny NS, Psaty BM, Newman AB, Siscovick D and Shlipak MG; Cardiovascular Health Study: Cystatin C concentration as a risk factor for heart failure in older adults. Ann Intern Med 142: 497-505, 2005.

18. Shlipak MG, Sarnak MJ, Katz R, Fried LF, Seliger SL, Newman AB, Siscovick DS and Stehman-Breen C: Cystatin C and the risk of death and cardiovascular events among elderly persons. N Engl J Med 352: 2049-2060, 2005.

19. Dolhnikoff M, Duarte-Neto AN, de Almeida Monteiro RA, da Silva LFF, de Oliveira EP, Saldiva PHN, Mauad T and Negri EM: Pathological evidence of pulmonary thrombotic phenomena in severe COVID-19. J Thromb Haemost 18 : $1517-1519,2020$

20. Zhang W, Zhao Y, Zhang F, Wang Q, Li T, Liu Z, Wang J, Qin Y, Zhang X, Yan X, et al: The use of anti-inflammatory drugs in the treatment of people with severe coronavirus disease 2019 (COVID-19): The Perspectives of clinical immunologists from China. Clin Immunol 214: 108393, 2020.

21. Channappanavar R and Perlman S: Pathogenic human coronavirus infections: Causes and consequences of cytokine storm and immunopathology. Semin Immunopathol 39: 529-539, 2017.
22. Chousterman BG, Swirski FK and Weber GF: Cytokine storm and sepsis disease pathogenesis. Semin Immunopathol 39: 517-528, 2017.

23. Zhou F, Yu T, Du R, Fan G, Liu Y, Liu Z, Xiang J, Wang Y, Song B, $\mathrm{Gu}$ X, et al: Clinical course and risk factors for mortality of adult inpatients with COVID-19 in Wuhan, China: A retrospective cohort study. Lancet 395: 1054-1062, 2020.

24. Ruan Q, Yang K, Wang W, Jiang L and Song J: Clinical predictors of mortality due to COVID-19 based on an analysis of data of 150 patients from Wuhan, China. Intensive Care Med 46: 846-848, 2020

25. Wu C, Chen X, Cai Y, Xia J, Zhou X, Xu S, Huang H, Zhang L, Zhou X, Du C, et al: Risk factors associated with acute respiratory distress syndrome and death in patients with coronavirus disease 2019 pneumonia in Wuhan, China. JAMA Intern Med 180: 934-943, 2020

26. Radbel J, Narayanan $\mathrm{N}$ and Bhatt PJ: Use of tocilizumab for COVID-19-induced cytokine release syndrome: A cautionary case report. Chest 158: e15-e19, 2020.

27. Zhang S, Li L, Shen A, Chen Y and Qi Z: Rational use of tocilizumab in the treatment of novel coronavirus pneumonia. Clin Drug Investig 40: 511-518, 2020.

28. Xu Z, Shi L, Wang Y, Zhang J, Huang L, Zhang C, Liu S, Zhao P, Liu H, Zhu L, et al: Pathological findings of COVID-19 associated with acute respiratory distress syndrome. Lancet Respir Med 8: 420-422, 2020.

29. Wei X, Zeng W, Su J, Wan H, Yu X, Cao X, Tan W and Wang H: Hypolipidemia is associated with the severity of COVID-19. J Clin Lipidol 14: 297-304, 2020.

30. Funderburg NT and Mehta NN: Lipid abnormalities and inflammation in HIV inflection. Curr HIV/AIDS Rep 13: 218-225, 2016.

31. Zidar DA, Juchnowski S, Ferrari B, Clagett B, Pilch-Cooper HA, Rose S, Rodriguez B, McComsey GA, Sieg SF, Mehta NN, et al: Oxidized LDL levels are increased in HIV infection and may drive monocyte activation. J Acquir Immune Defic Syndr 69: 154-160, 2015 .

(i) $\Theta$ This work is licensed under a Creative Commons

Attribution-NonCommercial-NoDerivatives 4.0 International (CC BY-NC-ND 4.0) License. 